\title{
CRISTIAN SEGURA: DA PAISAGEM AO ESPAÇO
}

Joana Aparecida da Silveira do Amarante

\section{RESUMO}

Fogo no museu (2010), trabalho realizado pelo artista argentino Cristian Segura propõe ao visitante um modo diferente de observar o museu. $O$ artista utiliza o dispositivo simulacro, pensado por Jean Baudrillard (1997), de modo a desencadear outras experiências, como um incêndio iminente. A partir disso, as imagens de destruição de Cristian Segura são puras imagens sem avesso, sem perspectiva, sem ilusão ou intenção de criar outra realidade, pois pertencem ao seu próprio domínio. Para Cristian Segura, cada trabalho é uma nova possibilidade de perceber os espaços esquecidos pela cidade e questionar os problemas das instituições de arte, não buscando uma representação de um passado ou futuro sentimental, mas ironizando os espaços urbanos e museológicos.

Palavras Chave

Cristian Segura, dispositivo, simulacro, espaço, Fogo no museu.

\begin{abstract}
Fire in museum (2010), art intervention by the argentine artist Cristian Segura offers the visitor a different way to look at the museum. The artist uses the device simulacra, designed by Jean Baudrillard (1997), to trigger other experiences, such as an imminent fire. Thus, Cristian Segura's images of destruction are pure images without reverse, without perspective, without illusion or intention to create another reality, because they belong to their own domain. For Cristian, every work is a new possibility to perceive the spaces forgotten by city and question the problems of art institutions, not seeking a representation of a sentimental past or future, but mocking the urban spaces and museums.
\end{abstract}

Keywords

Cristian Segura, device, simulacra, space, Fire in museum. 
O teórico Paulo Sérgio Duarte em seu texto para o catálogo da Bienal do Mercosul, Direções no novo espaço (2005), parte do raciocínio de que toda obra de arte possui uma relação e se constitui a partir de experiências entre observador e a obra. Ele ainda acrescenta que a história da arte pode ser construída ou escrita a partir da relação que as obras possuem com o espaço museológico/urbano e o observador, cuja noção muda de época para época, solicitando sempre uma nova ou velha experiência de acordo com o seu tempo ${ }^{1}$. Discuto aqui como essa vivência pode se dar a partir do emprego de dispositivos ${ }^{2}$, que possibilitam uma expansão das relações com os lugares urbanos públicos e/ou privados.

Michel de Certeau fala que a relação do pedestre com os lugares da cidade acarreta uma mudança, onde o lugar se transforma em espaço, pois "é de certo modo animado pelo conjunto dos movimentos que aí se desdobram" ${ }^{3}$. Entende-se com isso que o espaço é o lugar praticado a partir das ações do presente e modificado pelas vivências do espectador-pedestre. O espaço possui a capacidade de ser móvel, sendo por isso instável, e essa mobilidade é ativada através do conjunto de movimentos que nele acontecem.

A partir disso, entende-se que essa experimentação do espaço público ou privado, também é ocasionada a partir da interação com o corpo do observador-

\footnotetext{
${ }^{1}$ DUARTE, Paulo Sérgio. História da Arte e do Espaço - O Projeto. In: FIDELIS, Gaudêncio; FERREIRA, Glória; DE MEDEIROS, Maria Beatriz; DUARTE, Paulo Sérgio. Direções no novo espaço. Porto Alegre, Fundação Bienal do Mercosul, 2005.

${ }^{2}$ Termo que se refere a uma força exterior que possui a capacidade de capturar, orientar, influenciar nas opiniões, ou seja, são meios que mediam a vivência dos seres viventes e as coisas do mundo (Cf. AGAMBEN, Giorgio. O que é o contemporâneo? e outros ensaios. Chapecó: SC, Argos, 2009).
}

${ }^{3}$ CERTEAU, Michel. de. A invenção do cotidiano: 1. artes de fazer. 14. ed. Petrópolis: Vozes, 2008, p. 202. 
pedestre que suscita novas ou velhas experiências, com o intuito de provocar uma relação de maior aproximação com esses lugares que se põe cada vez mais distante na contemporaneidade. Essa transformação parte de pequenos dispositivos, pequenos jogos propostos pelo artista ao visitante, pois "os jogos dos passos moldam espaços. Tecem os lugares. Sob esse ponto de vista, as motricidades dos pedestres formam um desses 'sistemas reais cuja existência faz efetivamente a cidade"' 4.

Cristian Segura propõe novos jogos ao visitante de modo que ele se torne mais participativo nessa brincadeira de modificações espaciais permitindo, assim, que o observador experimente o museu com outro olhar, como no trabalho Fogo no museu (2010). Essa participação não se dá no sentido de entrar, andar ao redor, girar, manipular, mas é uma participação mais subjetiva e sutil, onde o observador pode experimentar o espaço de outras formas, com outros sentidos e memórias. $\mathrm{O}$ artista entende que, para isso, necessita utilizar como subterfúgios dispositivos que possam desencadear a experiência que ele espera, ou talvez, que o lugar queira. Os simulacros criados pelo artista simulam a destruição através de sensações das quais realmente acreditamos. Os simulacros não falam de uma ideia utópica, mas do incêndio iminente daquele museu.

Jean Baudrillard trabalha com o conceito de simulacro no livro $A$ arte da desaparição (1997) utilizando como referência a obra de Andy Warhol. O teórico observa que o artista "expõe ao máximo o mundo a si mesmo, que expõe o avesso da imagem e mostra a todos que o avesso nada esconde e que a imagem é toda superfície e vazio" 5. As imagens de destruição de Cristian Segura são puras imagens sem avesso, sem perspectiva, sem ilusão e sem intenção de criar outra realidade utópica, pois pertencem ao seu próprio domínio.

\footnotetext{
${ }^{4}$ ibdem, p. 176.

${ }^{5}$ BAUDRILLARD, Jean. A arte da desaparição. Rio de Janeiro: Editora UFRJ / N-Imagem, 1997, p.8.
} 


\section{O espaço apresentado como simulacro na obra de Cristian Segura}

Em 2010, através de um site specific, utilizando a forma gráfica de revistas em quadrinhos, o artista realizou uma intervenção nas janelas do Museu de Arte das Américas, Washington DC, intitulado Fogo no museu (Imagem 1), onde cola em vinil, labaredas de fogo e uma espessa fumaça saindo pelas aberturas do museu. A intervenção nos mostra a vulnerabilidade dos espaços institucionais a partir dessa simulação de incêndio.

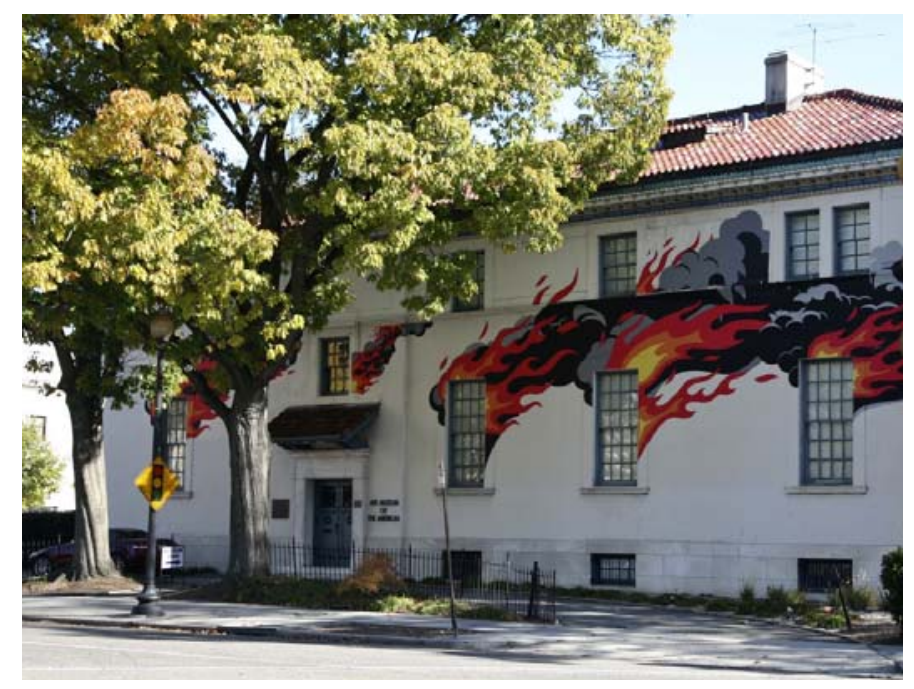

Imagem 1: Cristian Segura, Fogo no museu, 2010, intervenção site specific. Museu de Arte das Américas, Washington DC.

As construções históricas são normalmente mais vulneráveis a catástrofes como incêndios, porque normalmente esses museus se encontram em arquiteturas antigas que não possuem mecanismos de prevenção contra esse tipo de problema, como a existência de espaços compartimentados que ajudariam a limitar o fogo em determinadas áreas, de forma que não se espalhasse por toda a construção 
tornando, assim, mais fácil o trabalho de extinção das chamas ${ }^{6}$. O artista chama a atenção para o fato de que se acontecer um incêndio no museu, não seria somente perigoso para a estrutura física do espaço, mas também, para a estrutura interna, ou melhor, para os objetos que esses lugares guardam. Um incêndio poderia ocasionar o desaparecimento do patrimônio cultural que se encontra ali "protegido".

Cristian Segura apresenta essa mesma proposta (Imagem 2 e 3) na Galeria Baro, em São Paulo, no ano de 2011. A exposição consiste em imagens das paredes do museu de Washington DC com a intervenção de fogo e a documentação em vídeo da montagem/colagem do vinil nas janelas. Coloca ainda nas paredes da galeria, plotagens com o mesmo formato das janelas do Museu de Arte das Américas de onde saem labaredas de fogo e fumaça. Segundo o artista:

Con ello quise significar las diferentes maneras que tenemos de percibir el mismo trabajo según el contexto, ya que en el pasado Brasil sufrió dos perdidas irremplazables por el fuego. El 8 de Julio de 1978, un pavoroso incendio destruyó el Museo de Arte Moderna de Rio de Janeiro reduciendo a cenizas su valioso patrimonio. $Y$ más recientemente, en 17 de octubre de 2009, un incendio destruyó gran parte del acervo artístico y documental del artista brasileño Helio Oiticica (1937-1980) el cual se albergaba en una casa privada en Rio de Janeiro bajo la tutela de su familia. ${ }^{7}$

\footnotetext{
${ }^{6}$ Cristian Segura, em aula ministrada pela Prof. Dra Rosângela Miranda Cherem, no período de 05 a 09/12/2011, no curso História da Arte como Operação de Hipertexto, pertencente ao Programa de Pós Graduação em Artes Visuais/UDESC.

${ }^{7}$ SCHVARTZ, Daiana; AMARANTE, Joana Aparecida da Silveira do. Cristian Segura: o artista do desassossego. Palíndromo, Florianópolis, v. 7, p. 172-180, 2012-2013.
} 

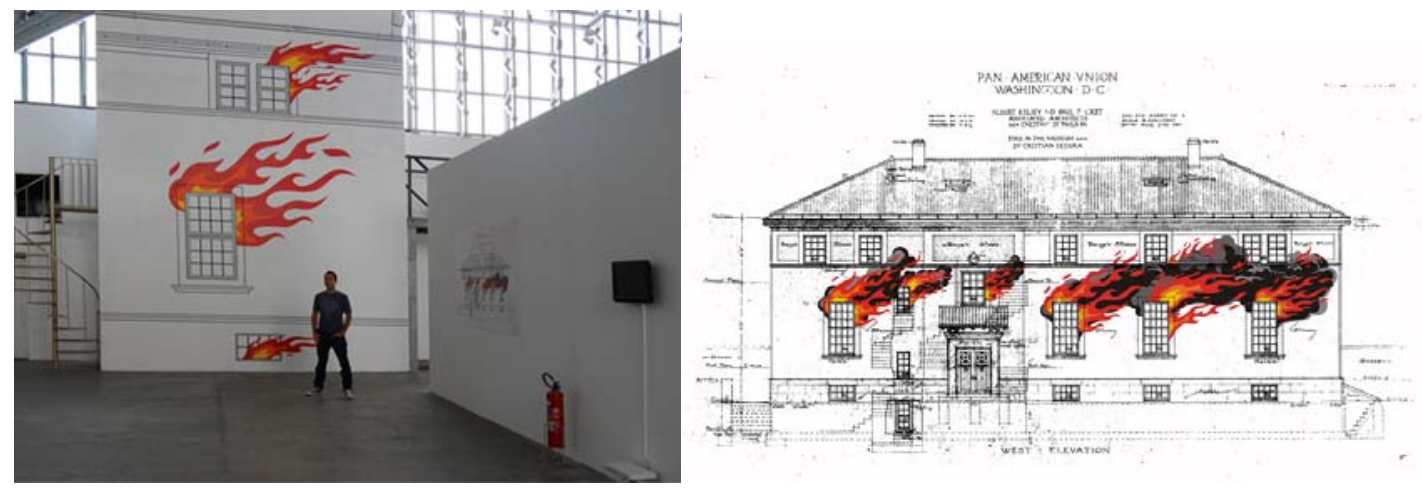

Imagem 2: Cristian Segura, Fogo no museu, 2010, intervenção site specific. Galeria Baro, São Paulo. (detalhe)

Imagem 3: Cristian Segura, Fogo no museu, 2010, intervenção site specific. Galeria Baro, São Paulo. (detalhe)

O teórico Jean Baudrillard fala que “(...) nós vivemos em um mundo de simulação, em um mundo em que a mais alta função do signo é fazer desaparecer a realidade, e mascarar ao mesmo tempo essa desaparição" 8 . O artista busca uma zona de perturbação através de dispositivos que possuem a capacidade de permitir outras experiências pelo observador. Aquelas situações tornam-se tão reais quanto a própria realidade, pois a iminência da destruição, permite que a ruína transforme-se em realidade.

\section{O espaço inventado de Cristian Segura por Morel e Jean Baudrillard}

Essa realidade explícita de destruição e ruína possibilitada através do uso de dispositivos pode ser observada através da experiência do fugitivo no livro do escritor Adolfo Bioy Casares, A invenção de Morel (2006), que trabalha literariamente com o simulacro, conceito proposto por Jean Baudrillard (1997). O teórico parte do princípio que a contemporaneidade está abarrotada de imagens, inclusive as de destruição e, colocar mais uma, seria somente mais outra imagem no meio de milhares sem significação alguma. Segundo o teórico "a arte nunca é o reflexo mecânico das condições positivas ou negativas do mundo, ela é sua ilusão exacerbada, o espelho hiperbólico", pois "no mundo voltado a indiferença, a arte só

\footnotetext{
${ }^{8}$ BAUDRILLARD, op. cit., p. 90.
} 
pode acrescentar a essa indiferença. Girar em torno do vazio da imagem, do objeto que não é mais objeto" 9 .

Jean Baudrillard acredita que a arte contemporânea caiu em sua própria armadilha, a de uma realidade irônica que não potencializa o real a partir de ilusões. A arte ironiza, finge o vazio e a insignificância como forma de significar, pois "é preciso que cada imagem subtraia da realidade do mundo, é preciso que em cada imagem alguma coisa desapareça" ${ }^{10}$.

$\mathrm{Na}$ narrativa de Adolfo Bioy Casares, um homem foge para uma ilha desconhecida com o intuito de esconder-se de seus perseguidores. Ele escapa para próximo de uma casa a qual chama de museu e, de repente, começam a surgir outras pessoas na ilha, que por um breve instante, pensa que estão atrás dele. $\mathrm{O}$ fugitivo se apaixona por uma das moradoras, Faustine, porém, por mais que tente estabelecer um contato com ela, não consegue, chegando a acreditar que seria ela ou ele que estaria morto(a). No final do livro, o autor deixa claro, que o personagem principal havia descoberto uma espécie de máquina filmadora, que não gravava somente imagens, mas também conseguia reter os cheiros, os paladares, o vento/brisa, a sensação do mar e da terra.

O filme que o fugitivo vê e acredita ser real, passa-se na ilha durante o verão. Durante a descrição dos relatos de seus dias e noites, percebemos que o personagem principal chegou durante o inverno. Descreve ainda que o local onde dormia, durante a maré cheia, ficava inundado e coberto por peixes mortos, o que tornava insuportável o lugar, mas durante o tempo em que se encontrava com Faustine, enxergava flores, sentia o cheiro de perfume, poderia até sentir a brisa do mar. Entretanto a máquina filmadora provocava uma espécie de doença que matou todas aquelas pessoas com as quais o personagem principal estava até então convivendo, mesmo que às escondidas, e seu fim não seria diferente do deles.

O que o fugitivo observa é a imagem da imagem, tão real quanto a própria realidade, um simulacro dela, por isso pensa que Faustine existe de verdade assim

\footnotetext{
9 ibdem, p. 84.

${ }^{10}$ ibdem, p.88.
} 
como ele. Numa das passagens do livro, podemos perceber com clareza essa confusão, no momento em que o fugitivo lê o diário de Morel, o inventor da máquina, no qual este fala:

Tive uma surpresa: depois de muito trabalho, ao congregar esses dados harmonicamente, encontrei pessoas reconstruídas, que desapareciam se eu desconectava o aparelho projetor, viviam apenas os momentos passados em que se gravara a cena e, ao terminá-los, voltavam a repeti-los, como se fossem partes de um disco ou de um filme que, uma vez terminado, tornasse a começar, mas que ninguém poderia distinguir das pessoas vivas (parecem circular em outro mundo, fortuitamente abordado pelo nosso). Se atribuímos consciência e tudo o que nos distingue dos objetos às pessoas que nos rodeiam, não poderemos negá-la àquelas criadas por meus aparelhos com nenhum argumento válido e exclusivo.

Congregados os sentidos, surge a alma. Era de se esperar. Madeleine estava ali para a visão, Madeleine estava ali para a audição, Madeleine estava ali para o paladar, Madeleine estava ali para o olfato, Madeleine estava ali para o tato. Madeleine estava ali. ${ }^{11}$

Entendo que Cristian Segura e o escritor Adolfo Bioy Casares trabalham com essa clave dos simulacros que possuem como objetivo o de questionar o princípio da realidade. O conceito se refere à imagem da imagem, portanto, ele torna-se outra coisa além de uma simples imagem, tal qual o fugitivo percebia Faustine, não como uma simples imagem, mas como uma realidade virtual tão real quanto se ela realmente existisse. O simulacro é a realidade, não é um "engana olhos" que tenta imitar outro espaço como o trompe-l'oeil, o simulacro é a sua imagem própria e pura. Segundo Jean Baudrillard:

A ilusão que procede da capacidade, através da invenção de formas, de separar-se do real, de contrapor-lhe uma outra cena, de passar para o outro lado do espelho, aquela que inventa um outro jogo e uma outra regra do

\footnotetext{
${ }^{11}$ BIOY CASARES, Adolfo. A invenção de Morel. São Paulo: Cosac Naify, 2006, p. 85.
} 
jogo, é impossível daqui para frente, porque as imagens passam para as coisas. Elas não são mais o espelho da realidade, elas investiram o cerne da realidade e o transformaram em hiper-realidade, onde, de tela a tela, não há outro destino para a imagem do que a imagem. A imagem não pode mais imaginar o real, uma vez que ela é o real, ela não pode mais transcendê-lo, transfigurá-lo, nem sonhá-lo, uma vez que ela é a sua realidade virtual. Na realidade virtual é como se as coisas tivessem engolido seu espelho. ${ }^{12}$

Os desastres que Cristian Segura nos apresenta são tão reais quanto o próprio desastre real. Ele produz imagens tão limpas, sem o excesso da destruição que vemos todos os dias pela televisão ou caminhando pelos espaços urbanos, que acaba criando outra realidade. O artista apresenta as labaredas saindo pelas janelas, o incêndio incontrolável, o momento em que os vidros se quebram e se esfacelam, podemos até perceber o som das chamas que ocasionam esse desastre estridente e aterrorizador, como uma realidade "presentificada" na obra de arte, o simulacro "experienciado".

Compreende-se que as obras de Cristian Segura não são representações de uma realidade, mas sim insinuações do real, ou seja, "ao invés de potencializar o real com a criação de ilusão" ${ }^{13}$, o artista argentino propõe um jogo no qual essa imagem ri de si mesma, não acrescentando, com isso, mais imagens na contemporaneidade. Para o artista cada trabalho é uma nova possibilidade de perceber esses espaços esquecidos pela cidade e questionar os problemas das instituições de arte, não buscando a representação de um passado ou futuro sentimental, mas ironizando os espaços urbanos e museológicos.

\footnotetext{
${ }^{12}$ BAUDRILLARD, op. cit., p. 91.

${ }^{13}$ ibdem, p. 7.
} 